\title{
O ENSINO DA GEOGRAFIA APLICADO À LEI 10.639
}

\author{
Pedro Dias Mangolini Neves ${ }^{1}$ \\ Aldenir Dias dos Santos ${ }^{2}$
}

\begin{abstract}
RESUMO
O objetivo desta pesquisa foi apresentar o projeto de intervenção pedagógica desenvolvido na Escola Municipal Professora Geni Chaves, localizada no município de Uberaba, Minas Gerais. Esta atividade contou com o envolvimento de alunos, professores e equipe pedagógica no nível Ensino Fundamental II (6ㅇ a 9o ano) tendo como foco o tratamento para a educação das relações étnico raciais de forma positiva, bem como o estudo da história e cultura afro-brasileira e africana. No que diz respeito à aplicação desta intervenção pedagógica, o professor da disciplina de Geografia aplicou, em diversas séries do Ensino Fundamental II, conteúdos que estão na Matriz Pedagógica, desenvolvendo atividades como produções cartográficas a partir da elaboração de banco de dados. Neste sentido, favoreceu-se o reconhecimento da memória histórica brasileira e afro-brasileira por meio da valorização da cultura das nações africanas, como análise e mapeamento da diáspora africana (70 ano) e análise e mapeamento dos reinos e impérios do continente africano (9o ano). Ao final do conteúdo, pode-se concluir que houve uma mudança na forma como o conteúdo foi transmitido aos alunos, colocando o professor como mediador de um conteúdo e não apenas como aquele que detém um saber, tornando as aulas mais ativas e reflexivas, fato que favoreceu uma maior compreensão da temática africana e afro-brasileira pelos alunos com o estudo e a observação dos mapas desenvolvidos.
\end{abstract}

Palavras-chave: Lei 10.639. Ensino de Geografia. Diáspora africana. Reinos e impérios africanos.

THE GEOGRAPHICAL EDUCATION APPLIED TO LAW 10.639

\begin{abstract}
The objective of this research was to present the project of pedagogical intervention developed at the Municipal School Teacher Geni Chaves located in the municipality of Uberaba, Minas Gerais. This activity had the involvement of students, teachers and pedagogical staff at elementary level II (6th to 9th grade) focusing on the treatment for the education of racial ethnic relations in a positive way, as well as the study of Afro- Brazilian and African. Regarding the application of this pedagogical intervention, the teacher of the Geography discipline applied, in several series of elementary education II, contents that are in the Pedagogical Matrix by developing activities, such as, cartographic productions from the elaboration of database. In this sense, the recognition of Brazilian and Afro-Brazilian historical memory was favored through the valorization and culture of African nations, such as the analysis and mapping of the African Diaspora (7th year) and the analysis and mapping of African kingdoms and empires (9th year). At the end of the content, it can be concluded that there was a change in the way in which the content was transmitted to the students, placing the teacher as mediator of a content and not only as the one that holds a knowledge, making the classes more active and reflective, a fact that favored a greater understanding of the African and Afro-Brazilian themes by the students through the study and observation of the developed maps.
\end{abstract}

Keywords: Law 10.639. Geography teaching. African diaspora. Kingdoms and african empires.

Recebido em: 20/11/2018

Aceito em: $18 / 12 / 2018$

\footnotetext{
${ }^{1}$ Doutor em Geografia no Programa de Pós-Graduação em Geografia da Universidade Federal de Goiás - UFG. Professor PEB II (60 a 9o ano) do Município de Uberaba - Disciplina: Geografia. pmangolini@hotmail.com

${ }^{2}$ Doutora em Ciências Sociais pela Pontifícia Universidade Católica de São Paulo - PUC-SP. Mestre em Educação pela Universidade Metodista de Piracicaba - Unimep - e membro do Coletivo Feminista Maria Vai com as Outras. dias.dida@gmail.com
} 
Apesar da estreita relação existente entre o continente africano e o Brasil, a história e cultura desses povos, o respeito e o espaço para as manifestações de suas tradições em nosso país permanecem desconhecidas, relegadas e, quando não estão ausentes no imaginário popular, ocupam um lugar periférico e repleto de estereótipos a respeito da formação do povo brasileiro. Diante disso, ressalta-se o ensino de Geografia, com todo seu arcabouço teórico e crítico, como um importante movimento para se contribuir com a compreensão das dinâmicas históricas e geográficas que o período histórico da colonização até os dias atuais demanda.

A ausência de conhecimento da história e cultura africana e afro-brasileira dos alunos repercute na população brasileira. Isso é perceptivel quando ela nega sua própria tragetória de pluralidade cultural e genética. Como tentativa de superar um modelo de ensino pouco articulado e reflevixo, em 2003 foi sancionada a Lei 10.639 (BRASIL, 2003), que modifica a Lei de Diretrizes e Bases (LDB - Lei n. 9.394/1996), tornando obrigatória a inclusão no currículo oficial da Rede de Ensino (público e privado) a temática "História e Cultura Afro-Brasileira».

Ações pedagógicas educacionais que possibilitem o conhecimento e reconhecimento dessa história e da memória brasileira e afro-brasileira (e consequentemente africana) por meio da valorização da história e cultura das nações africanas e americanas, são imprescindíveis. Isso permite entender o movimento de captura dos africanos: sequestros de, muitas vezes, técnicos altamente especializados que viviam em sociedade e produzindo naquele continente para serem escravizados no Brasil; essa característica teve papel primordial no desenvolvimento dos ciclos econômicos do Brasil e na construção deste país.

Como destaca Hugh Masekela (O PAÍS, 2017), músico sul-africano,

Os povos africanos devem resgatar os seus valores culturais, que encontram bases na língua, como um instrumento de identidade primária. [...] Temos que conhecer os valores das nossas línguas, pois elas conferem-nos uma emancipação cultural. [...] O conhecimento da História de África, datada há milhões de anos, é a única forma de preservação das nossas bases culturais, numa altura em que a globalização coloca os africanos à margem das suas culturas. [...] Não podemos deixar de lado os nossos rituais, a componente indígena do africano é sempre importante para a compreensão da história. [...] A África vive um contexto de clamorosa perda de valores, sendo urgente uma tomada de medidas, por forma a reverter-se o cenário. [...] A comunidade africana é a única, no mundo, que copia os outros povos. Temos que fazer as nossas coisas. Temos que acreditar que podemos fazer mais coisas boas, e deixarmos de copiar os outros.

Diante disso, partimos do pressuposto de que a ignorância (falta de conhecimento) é a força motriz do racismo e da baixa autoestima da população negra no Brasil; logo, o conhecimento e o reconhecimento crítico da história e cultura africana e afro-brasileira, com sua relevância intelectual e habilidades profissionais das diferentes populações do continente africano para o desenvolvimento da sociedade brasileira, poderá devolver senso crítico, empoderamento e orgulho que lhes foram estirpados historicamente nos alunos e na família destes alunos. 
Neste sentido, este artigo teve como objetivo apresentar um trabalho que se propõe à aplicação da lei no 10.639/2003 na matriz pedagógica de uma escola do município de Uberaba (MG), com o intuito de promover criticamente o conhecimento e o reconhecimento do papel histórico-geográfico que as populações afro-brasileiras tiveram no desenvolvimento econômico, social e cultural do país. Trata-se, portanto, de um relato de experiência de uma intervenção pedagógica que emergiu a partir da inquietação do professor responsável pela disciplina de Geografia no Ensino Fundamental II (6으 a 9o ano), durante o ano letivo de 2018. O incômodo dava-se principalmente pela falta de compreesão dos alunos pelas temáticas relacionadas às relações étnico-raciais e afrobrasileiras, e, para que as discussões tivessem o efeito esperado, fugindo do modelo tradicional de ensino, utilizou-se metodologia ativa ${ }^{3}$ e posterior análise e discussão sobre os resultados alcançados.

Para colocar em prática esta metodologia foi definido, primeiramente, os sujeitos da pesquisa: alunos do 70 e 9o anos da Escola Municipal Professora Geni Chaves, localizada no município de Uberaba (MG). Em um segundo momento foram determinados dois objetivos específicos: a) compreender e mapear a diáspora africana para o Brasil, identificando nas redes de tráfico de escravidão para o Brasil as diversas nações que compuseram nossa identidade cultural (7ㅇano); b) compreender e mapear impérios africanos e identificar suas influências na contemporaneidade (9oano).

Posteriormente, foram realizadas duas atividades com diferentes turmas de forma concomitantemente. Assim, foi proposto para duas turmas do 70 ano a pesquisa das quatro diferentes rotas do tráfico negreiro que existiu entre o continente africano e o Brasil, com o intuito de identificar a origem (com a identificação do grupo étnico destas pessoas e o seu destino para a escravidão, o período e a quantidade da população retirada da sua terra - e de seus lares) e para qual ciclo econômico no Brasil foi utilizado.

Tais informações serviram para que nossas alunas e nossos alunos pudessem compreender que os povos africanos não foram somente os braços e pernas que construíram o Brasil, mas foram, também, o cérebro, o conhecimento técnico-científico utilizados no desenvolvimento econômico do Brasil, como nos ciclos econômicos canavieiro e da mineração, como descreve Fonseca (2004).

Já com a turma do 9o ano foi proposta a pesquisa dos diferentes reinos e impérios que existiram no continente africano, a fim de identificar a localização destas sociedades, o período e qual era o seu desenvolvimento técnico-científico, objetivando que os alunos compreendessem que no Continente Africano havia e há sociedades com o desenvolvimento intelectual igual ou superior a povos de outros Continentes e de que não é um Continente apenas com miséria e fauna selvagem.

\footnotetext{
${ }^{3}$ Método Ativo é o processo de ensino em que os estudantes ocupam o centro das ações educativas por meio da problematização da realidade, como estratégia pedagógica, com o objetivo de alcançar e motivar os aprendizes à construção de conhecimentos, competências e habilidades, sejam humanas ou profissionais, considerando que, ante o problema que eles se envolvem, examinam, refletem e estabelecem relações, atribuindo novos significados para suas descobertas.
} 
Depois destas duas etapas, todos os dados pesquisados pelos alunos foram sistematizados e utilizados para elaboração de dois mapas. O primeiro refere-se ao Mapa dos reinos e impérios africanos (Figura 2) e o segundo ao Mapa da diáspora africana século 16 a 19 (Figura 3).

Por fim, para encerrar esse conteúdo programático, foram aplicadas questões aos alunos que participaram da atividade, antes e depois do desenvolvimento do trabalho, para avaliar o conhecimento prévio e o que foi adquirido a partir da atividade. Para o 7응 ano foi questionado: $O$ que foi a diáspora africana? Quem foram os escravizados trazidos da África para o Brasil e como eles viviam? E para os alunos do 9 ano foi questionado: O que você conhece do Continente Africano? Qual a história da África? Qual o nível de conhecimento/desenvolvimento econômico do Continente Africano?

\section{REINOS E IMPÉRIOS AFRICANOS}

Existem alguns autores contemporâneos com críticas à escola e à universidade brasileira que, ao estudarem o Continente Africano, discutem apenas a partir da colonização europeia, excluindo seu passado e, consequentemente, a história das civilizações africanas com seu desenvolvimento técnico-científico. Segundo Santos (2016), foram produzidas ideias de inferioridade sobre grupos humanos a partir de diferenças biológicas e culturais, naturalizando desigualdades criadas. Ou seja, são apresentados ao educando apenas 500 anos de história, descartando os outros milhares ou milhões de anos, se destacarmos que a história da humanidade se iniciou neste Continente. Apresentam, também, uma história única contada pelos europeus por meio de uma educação eurocêntrica.

Fonseca (2008) destaca que a África subsaariana, principalmente, foi desprezada pelas sociedades e sistemas de ensino ocidentais aparentemente pela ideia de que ela fosse destituída da escrita e, consequentemente, do saber, porém as diferentes etnias utilizaram-se de veículos diversos para propagar o saber, por exemplo, a oralidade, sobretudo nas sociedades subsaarianas, e a escrita, como os Akan e Manding, que originaram a escrita egípcia e meroítica (Sudão), segundo Nascimento (1996). Fonseca (2004) relembra que o Continente Africano, além de ser o berço da humanidade, é, também, o das civilizações, com atividades de agricultura, criação de gado, metalurgia e várias outras especializações ocupacionais.

Conforme Nascimento (1996), foi na África que ocorreu a primeira revolução tecnológica da humanidade - a passagem de caçador e coletor de frutos e raízes para a agricultura e pecuária -, conhecida pelo nome de Revolução Neolítica, que, consoante Guilherme Altares em El País (2018), foi o período mais importante da história. Foi neste período que nasceu a aristocracia, a divisão de poderes, a guerra, a propriedade, a escrita e o crescimento populacional. Surgiram, em poucas palavras, os pilares do mundo em que vivemos. As sociedades atuais são suas herdeiras diretas: nunca fez tanto sentido falar de revolução, porque deu origem a um mundo totalmente novo.

Foi naquele período que a humanidade começou a transformar o meio ambiente para adaptá-lo às suas necessidades, e quando a população da Terra começou a crescer exponencialmente, um processo que só se acelerou desde então. De acordo com 
Nascimento (1996), a pecuária apareceu há 15 mil anos atrás, perto da atual Nairobi (Quênia), sendo que está técnica só se espalhou pelos vales dos rios Tigres e Eufrates séculos depois.

Demoule, que escreveu o livro "Os Dez Milênios Esquecidos Que Fizeram a História. Quando Inventamos a Agricultura, a Guerra e os Chefes", em 2017, em entrevista para o El País (2018), acredita

\begin{abstract}
que é a única verdadeira revolução na história da humanidade. A revolução digital que estamos vivendo atualmente não é mais do que uma consequência de longo prazo daquela. Mas, curiosamente, é a menos ensinada na escola. Começamos com as grandes civilizações, como se fossem óbvias, mas é muito importante perguntar por que chegamos até aqui, por que temos governantes, exércitos, burocracia. Acho que no nosso inconsciente não queremos fazer essas perguntas (EL PAÍs, 2018).
\end{abstract}

O fato do desconhecimento da história e cultura africana não é acidental, mas, sim, proposital, segundo Nascimento (1996). O saque empreendido no Continente Africano e a destruição da Biblioteca de Alexandria comprovam o apagamento dos conhecimentos africanos, tornando-os apenas exóticos e místicos, apresentando, assim, uma única história da humanidade - a história da humanidade do ponto de vista europeu e, consequentemente, ocidental.

Fonseca (2008) discorre sobre os exemplos de influência africana na ciência, como o saber médico (com a mumificação egípcia há 5 mil anos; cirurgia de cataratas há 4500 anos no Mali e Egito; Cirurgia de Cesária, assepsia, anestesia, hemostasia e cauterização na região de Uganda; Vacinação e farmacologia com os Banyoro), as técnicas e saberes da engenharia (como os Haya [Tanzânia] no ano zero, que já forjavam aço em fornos mais quentes do que na Revolução Industrial; a cidade murada de Monomatapa que durou 300 anos; Pirâmides na África e na América, o que indica intercâmbio científico e cultural; construção de navios há 4600 anos, superiores às Naus dos portugueses e conhecimento das correntes marítimas), os conhecimentos e cálculos matemáticos e astronômicos (com observatórios no Quênia em 1000 a.C.) e o conhecimento do Sistema Solar e Via Láctea há 700 anos a.C.

Além desses fatores, há também as influências sociais e antropológicas que atingem desde a América até a Europa e a Ásia há milhares de anos, como em deslocamentos migratórios contemporâneos, como os Mouros, que ocuparam a Espanha e Portugal, ou em fósseis encontrados no México entre os Olmecas (sociedade anterior aos maias); na relação do imperador do Mali em 1300 d.C. com Deus Serpente emplumado; e nas mitologias escandinavas a presença de homens negros (possivelmente nas "aventuras" de marinheiros africanos que tentaram invadir a Irlanda).

Segundo Nascimento (1996), o conhecimento naval africano é antigo. Desde 2600 a.C. construíam navios de grande porte, com capacidade superior às naus europeias que chegaram à América mais de dois milênios depois. Vale ressaltar que algumas nações do continente africano conheciam as rotas marítimas, o que chamavam de "rios no meio do mar", tendo como exemplo o imperador Mali, Abudakari II, que, em 1311, chegou ao litoral do México. 
Esse conhecimento naval, cultural e científico africano que proporcionou a chegada de Colombo e de Cabral nas Américas, foi apropriado pelos portugueses que tiveram acesso a tais informações quando passaram a traficar matérias-primas e pessoas da África Ocidental para a Europa; deste modo, passaram a utilizar as cartas náuticas elaboradas pelos africanos do norte e do ocidente (NASCIMENTO, 1996).

\section{DIÁSPORA AFRICANA PARA O BRASIL}

Diáspora é um substantivo feminino com origem no termo grego diasporá, que significa dispersão de povos por motivos políticos ou religiosos. Este conceito surgiu pela primeira vez graças à dispersão dos judeus no mundo antigo, principalmente depois do exílio babilônico; dispersão que continuou a ocorrer ao longo dos séculos, como no caso de povos africanos que foram sequestrados de sua terra natal e levados para a América, Europa e Ásia por aproximadamente 300 anos.

Os africanos que foram trazidos para o Brasil, conudo, não chegaram aqui sozinhos. Trouxeram suas divindades, visões do mundo, alteridades - linguística, artística, étnica, religiosa -, diferentes formas de organização social, diversos modos de simbolização do real e conhecimentos.

Três séculos foram marcados pela presença de um comércio de seres humanos, que trouxe para o Brasil de 3,6 a 5,5 milhões de pessoas da África subsaariana, oriundas, principalmente, das regiões que compunham a África Ocidental e a Centro-Ocidental, e da África Oriental em menor escala (CURTIN, 1969). Cada região tinha sua própria história e se desenvolvia em passos diferentes e com distintas ênfases.

Segundo Russell-Wood (2001), o continente africano poderia também ser caracterizado por uma produção econômica voltada ao artesanato e forjamento de metais, em particular na África Ocidental e na Centro-Ocidental. Minas de ouro eram exploradas na África ocidental e na oriental. Deste modo, havia presença, no continente, de metalúrgicos sofisticados e artesãos especializados na produção de objetos de metais.

Já os sistemas de produção de alimentos incluíam a agricultura, a caça, a pesca, a criação de gado, a coleta de frutas e legumes e as economias mistas. Na África oriental, como em outros lugares, havia distinções significativas entre as regiões agrícolas e de pastoreio (RUSSELL-WOOD, 2001).

No Brasil colonial o trabalho escravo supria as demandas de uma economia de exportação, por intermédio de ciclos econômicos ditados principalmente pela Europa. Além das habilidades profissionais destes africanos, os proprietários definiam suas preferências por tipos de escravizados, em termos de uma espécie de política de aquisição, com base na faixa etária, no sexo e na cor, e também em termos de local de nascimento, indicando, assim, sua especialização.Vários pesquisadores, como Russell-Wood (1977), Carney (2001), Fonseca (2008) e Anjos (2011), dentre outros, trazem argumentos plausíveis de que no Brasil colonial e na América Anglo-Saxã Continental (EUA), parte destes escravizados possuíam conhecimento anterior do cultivo agrícola, do controle de água para irrigação e de tecnologias de mineração. Isto fez com que estes países priorizassem determinadas nações na África para a retirada destes trabalhadores e trabalhadoras. 
Deste modo, tecnologias na agricultura e mineração, que foram utilizadas para o desenvolvimento econômico na América, iam sendo transferidas não da Europa, mas da África para a América; assim, segundo Fonseca (2008), este povo africano civilizou este país.

O tráfico africano em direção à Europa iniciou no início do século 15 para Portugal, para atender as demandas econômicas existentes naquele país e a das Ilhas de Açores e Madeira, além de abastecer Lisboa desta mão de obra estrangeira. Muitos destes africanos, sequestrados para Portugal e para suas ilhas e colônias, como Cabo Verde e Santo Tomé e Príncipe, nascidos na Guiné, foram os primeiros a serem transportados para o Brasil já nas primeiras rotas de tráfico no início de 1500 , tendo em vista a plantação de cana-de-açúcar já existente no mediterrâneo e nas ilhas ibéricas (MILLER, 1997; ALENCASTRO, 2000), fato já conhecido historicamente, porém o que é propositalmente esquecido é o motivo da utilização específica de povos da Guiné para este tipo de cultivo.

Conforme Chiavenato (1986), Portugal trazia para o Brasil uma população que conhecia a tecnologia agrícola da cana-de-açúcar, principalmente em Guiné e em Angola.

Com a alteração da importância do ciclo econômico vigente no Brasil - do ciclo da cana-de-açúcar para a mineração -, havia a necessidade de uma mão de obra especializada para este tipo de serviço.

Para Fonseca (2008), com a centralização da atividade econômica focada na mineração houve a necessidade de buscar nova população africana, mais afeita às tecnologias de extração mineral, como populações do grupo linguístico Bantu de regiões moçambicanas e de Madagascar, por exemplo.

Chiavenato (1986) acrescenta que muito desses povos agricultores, pastores e mineradores tinham técnicas mais avançadas do que portugueses, sendo muito hábeis no conhecimento em relação à metalurgia e siderurgia. $O$ povo Yoruba, por exemplo, já trabalhava com cobre e estanho, trazendo tais conhecimentos para o Brasil; já os ganenses e nigerianos trouxeram o conhecimento da enxada de ferro.

Deste modo, os povos das diferentes culturas da África foram responsáveis por um grande legado deixado para o Brasil, tanto na musicalidade e culinária quanto, também, nas ciências e tecnologias, muito bem destacado por Querino (1988), como nas artes em geral e culinária.

Foi o trabalho do negro que aqui sustentou por séculos e sem desfalecimento, a nobreza e a prosperidade do Brasil; foi com o produto do seu trabalho que tivemos as instituições científicas, letras, artes, comércio, indústria, etc., competindo-lhes, portanto, um lugar de destaque como fator da civilização brasileira.

Quem quer que compulse a nossa história, certificar-se-á do valor e da contribuição do negro na defesa do território nacional, na agricultura, na mineração, como bandeirante, no movimento de independência, com as armas na mão, como elemento apreciável na família, e como herói do trabalho em todas as aplicações úteis e proveitosas (p. 122).

A partir destes fatos destacados pode-se compreender a importância do conhecimento técnico-científico dos povos africanos escravizados para o desenvolvimento da sociedade brasileira, bem como a formação territorial do Brasil. Tais informações, po- 
rém, não estão presentes na formação educacional brasileira e, deste modo, não fazem parte do ambiente escolar, por negligência de professores e falta de materiais de estudo (apostila e livros didáticos), justificando a necessidade de intervenções pedagógicas como esta.

\section{RESULTADOS}

A geografia é a área do conhecimento que tem o compromisso de tornar o mundo e suas dinâmicas compreensíveis para a sociedade, de dar explicações para as transformações territoriais e de apontar soluções para uma melhor organização do espaço. Deste modo, a geografia é uma ciência fundamental na formação da cidadania do povo brasileiro, que apresenta uma heterogeneidade singular na sua composição étnica, socioeconômica e na distribuição espacial.

Como ferramenta primordial para a geografia temos a cartografia, que se utiliza da representação gráfica com mapas para elucidar os acontecimentos do mundo real. Os mapas possibilitam revelar graficamente o que acontece na dinâmica do espaço e tornam-se cada vez mais imprescindíveis, por se constituírem numa sintetização e simplificação destas diferentes dinâmicas que facilitam a observação da realidade. Diante disso, utilizou-se em sala de aula uma técnica da cartografia como metodologia ativa disparadora para melhor representar a distribuição dos reinos e impérios no Continente Africano e da diáspora africana.

Como já citado, foram realizados alguns questionamentos aos alunos sobre o conhecimento prévio a respeito da diáspora africana, bem como sobre os reinos e impérios africanos, e também sobre como compreendem o desenvolvimento técnico-científico das diferentes nações africanas. Pode-se elencar, pelas respostas dos alunos, tanto do 70 quanto do 9o ano, que o conhecimento majoritário sobre Continente Africano é de este ser uma extensa área com grandes animais, como leões e elefantes, uma permanente existência de conflitos e guerras e com muita miséria e fome nas aldeias, sem menção alguma de sociedades estruturadas, a não ser quando relatam do Egito, além da confusão numa crença de que este país pertença ao Continente Europeu e continuarem a pensar que a África é um país.

A compreensão do Continente Africano como uma região de diversos conflitos e guerras vem da real ocorrência dos conflitos étnicos em algumas regiões, que foram provocados propositalmente quando os países europeus no período colonial, por meio da Conferência de Berlim (em 1884), em que foi realizada a divisão do Continente Africano, não respeitaram a diversidade política e cultural desses povos (Figura 1), resultando na união de grupos rivais num mesmo território ou país no período pós-colonial, e, assim, como consequência, surgiram diversos conflitos no continente, influindo na situação de extrema pobreza destes países. 
Figura 1 - Mapa étnico do continente africano e mapa político do continente africano
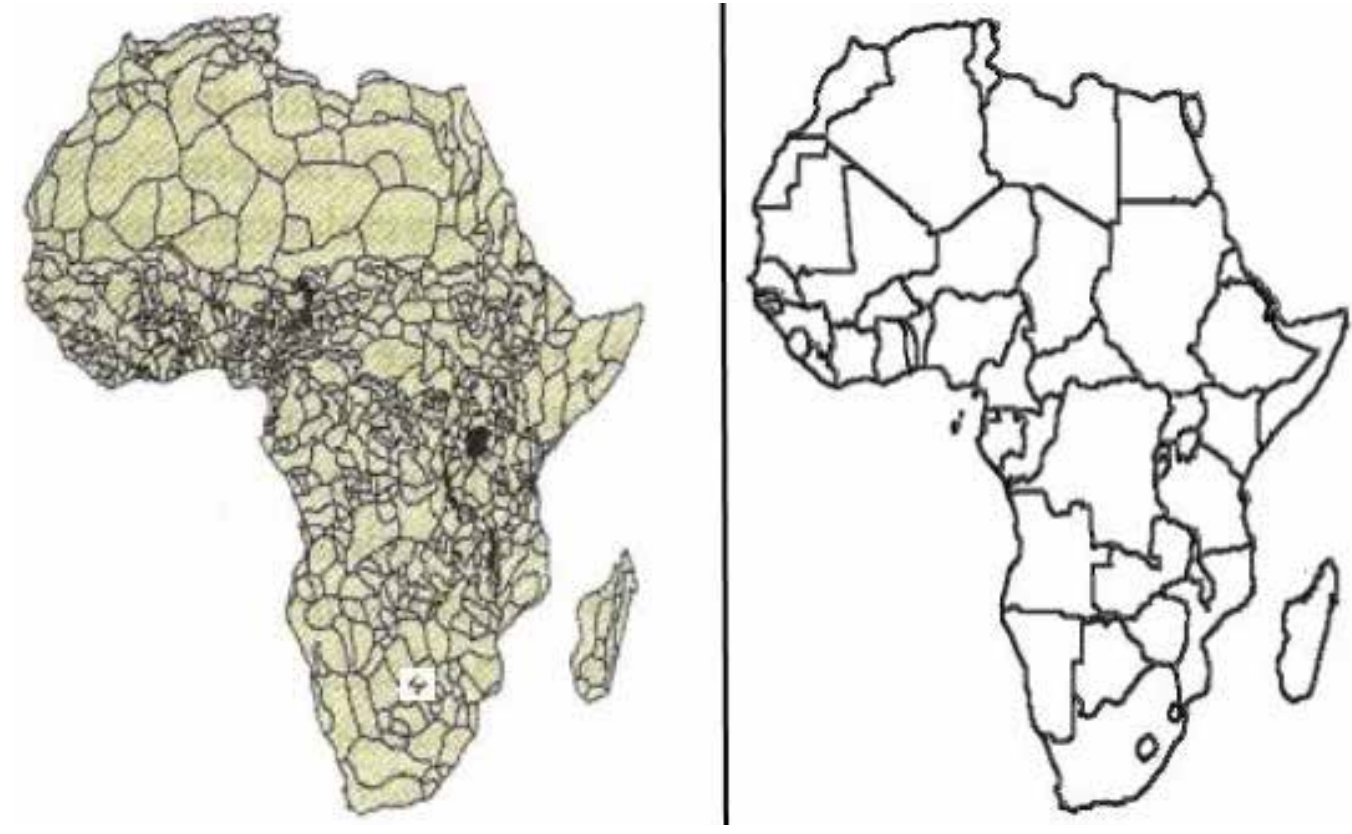

Fonte: Adaptado de GLASSNER, 1996.

Posteriormente os alunos do 9o ano desenvolveram um banco de dados com informações sobre os diferentes reinos e impérios do Continente Africano, e foi elaborado um mapa contendo tais informações com a localização geográfica destes povos neste Continente, como pode ser observado na Figura 2.

Figura 2 - Mapa dos Reinos e Impérios Africanos
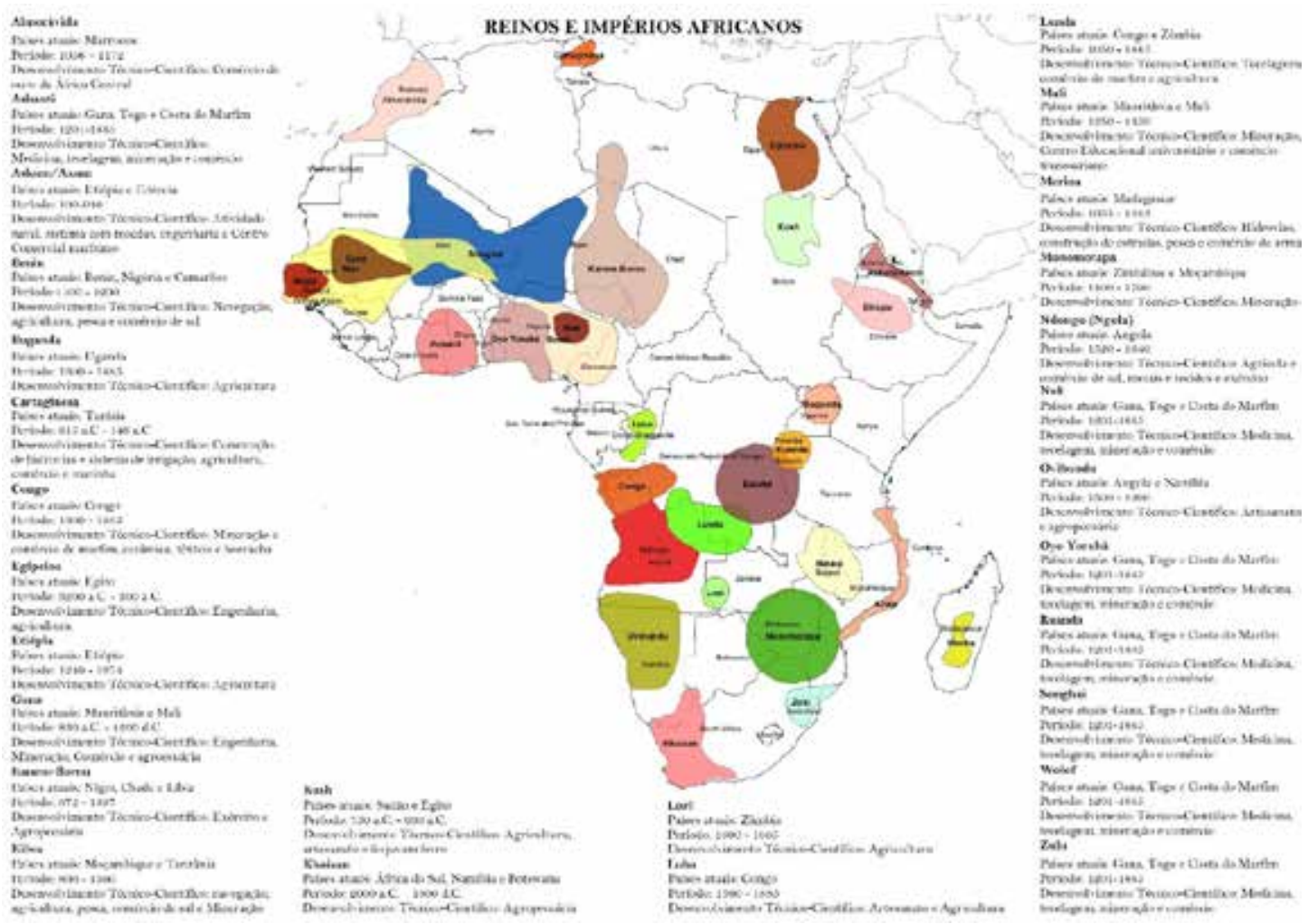

Fonte: Os autores, 2018. 
Percebe-se a inúmera quantidade de reinos e impérios que existiram no Continente Africano, em diferentes períodos, com diversas etnias e regiões, reproduzindo-se por meio das várias atividades, com inúmeros conhecimentos técnico-científicos, como o desenvolvimento de técnicas agrícolas, irrigação, técnicas em tecelagem e cerâmica, até técnicas de siderurgia e metalurgia.

Concomitantemente a esta atividade, os alunos do 70 ano pesquisaram e abasteceram um banco de dados sobre a diáspora africana, destacando informações como origem e destino das diferentes rotas de escravizados do Continente Africano para o Brasil, informando também para quais ciclos econômicos no Brasil foram utilizados esses homens e mulheres que vieram sequestrados de seu país de nascimento. Tais informações foram importantes para a elaboração do Mapa da Diáspora Africana dos séculos 16 a 19 (Figura 3).

Figura 3 - Mapa da diáspora africana - séculos 16 a 19

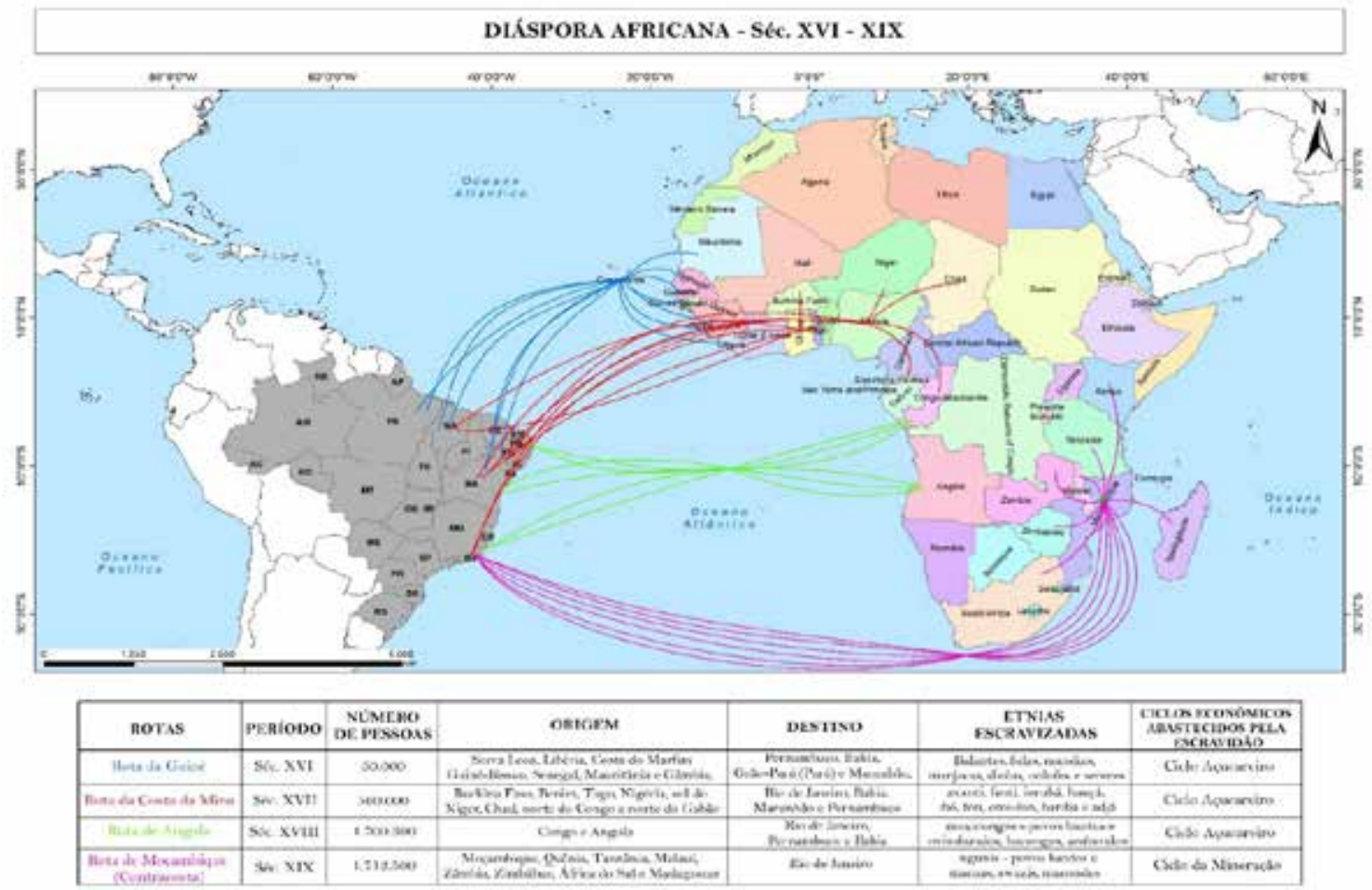

Fonte: Os autores, 2018.

Existiram quatro principais rotas de navios negreiros que ligavam a África ao Brasil: Rota da Guiné, Rota da Mina, Rota de Angola e Rota de Moçambique (Contracosta), que trouxeram entre quatro a oito milhões de seres humanos escravizados e sequestrados de suas terras para serem utilizados como mão de obra neste país.

Podemos observar diferentes utilidades para aqueles que foram trazidos à força para nosso país e escravizados. A população com origem na África Ocidental foi, principalmente, utilizada no desenvolvimento do ciclo da cana-de-açúcar; já os escravizados sequestrados da África Oriental foram usados para o desenvolvimento do ciclo da mineração. Esta vinda e distribuição não se deu por acaso. De acordo com as informações 
contidas no Mapa de Reinos e Impérios Africanos (Figura 2), são regiões que possuíram povos com desenvolvimento técnico-científico relacionado, respectivamente, à agricultura e à mineração.

Após a elaboração dos mapas, foram reaplicados os questionamentos sobre a diáspora africana e o desenvolvimento técnico-científico das diferentes nações africanas, a fim de compreender se houve algum estímulo para os alunos com esta metodologia de ensino-aprendizagem.

Para os mesmos questionamentos, após ser realizado o desenvolvimento desta pesquisa e se observar os dois mapas, houve diferentes respostas; por exemplo, um aluno (7음 ano) que escreveu: "os escravizados foram sequestrados e trazidos da África durante a 'diáspora africana' que viviam em aldeias e tribos, como os bantu e os yorubá", e outro aluno, também do 70 ano, expressou: "Os escravizados trazidos para o Brasil vivam em aldeias e tribos e tiveram muita importância no desenvolvimento do Brasil pois tinham novos conhecimentos, como de mineração e de agricultura".

Uma aluna do 9 o ano desmistificou o conceito anterior e sintetizou muito bem sua nova percepção da história ao descrever que "o continente africano é rico em conhecimento e em tecnologia, como os de conhecimento naval e de medicina, e por isso foram importantes para o desenvolvimento do Brasil, pois foram utilizadas suas técnicas aqui durante a escravidão".

Deste modo, percebe-se que houve uma maior compreensão da temática africana e afro-brasileira pelos alunos, pela pesquisa e posterior observação dos mapas desenvolvidos por intermédio do banco de dados criado pelos próprios alunos.

\section{CONSIDERAÇÕES FINAIS}

A questão do desconhecimento da população brasileira no que se refere ao Continente Africano é um entrave para uma perspectiva real de democracia racial na estrutura do país. Não podemos perder de vista que entre os principais obstáculos criados pelo sistema para a inserção da população de origem africana na sociedade brasileira, está a inferiorização deste grupo social em razão das ideias predominantes sobre a história e cultura africana e de seu povo. Esse contexto somente poderá mudar com uma política educacional com foco direcionado para desmistificar o Continente Africano para a população brasileira.O brasileiro não pode mais ter a compreensão de que a África é um país; nem que lá existem somente doenças, seres humanos e culturas primitivas (no sentido preconceituosos de cultura inferior) e espaços para safári com animais exóticos. Tais conhecimentos preestabelecidos auxiliam na manutenção de uma população preconceituosa às referências africanas e seus descendentes brasileiros. Este é um ponto estrutural para um processo de mudança e de valorização, quando o ser humano brasileiro de ascendência africana e toda a população brasileira sejam respeitados.

Acreditamos no processo educacional como um elemento de transformação e de reconstrução dos conteúdos e informações de uma história única, como ferramentas para ampliação do conhecimento da humanidade, desfazendo, assim, estereótipos em relação aos povos que não os de origem europeia. 
Tomamos como premissa que as informações por si só não significam conhecimento. Por isso, quando o educando faz parte da investigação e da elaboração de um material didático, ele acaba compreendendo melhor as dinâmicas e os conteúdos envolvidos.Com este estudo de caso observou-se que houve uma maior compreensão da temática africana e afro-brasileira pelos alunos envolvidos nesta pesquisa, com posterior elaboração de um banco de dados e de seu resultado final, com o Mapa dos Reinos e Impérios Africanos e com o Mapa da diáspora africana para o Brasil.Deste modo, mediante este projeto pode-se compreender que, com uma participação ativa e crítica do professor em sala de aula, é possível mudar as estruturas do sistema para a aplicação da Lei 10.639 , bem como perceber os resultados práticos na vida dos estudantes quando se trabalha com metodologias ativas de ensino-aprendizagem, como a percepção e o entendimento da importância dos conhecimentos técnicos e culturais das diferentes etnias e povos do Continente Africano, com a possibilidade de um trabalho integrado entre as diversas séries do Ensino Fundamental II, e análise crítica e transformação social desde a base do ensino.

\section{REFERÊNCIAS}

ALENCASTRO, Luiz Fernando de. O trato dos viventes: formação do Brasil no Atlântico Sul. São Paulo: Cia das Letras, 2000.

ANJOS, Rafael Sanzio Araújo dos. Cartografia da diáspora África - Brasil. Revista da Anpege, Presidente Prudente, SP, v. 7, n. 1, número especial, p. 261-274, 2011.

BRASIL. Lei 10.639/2003, de 9 de janeiro de 2003. Altera a Lei no 9. 394, de 20 de dezembro de 1996. Diário Oficial da União, Poder Executivo, Brasília, 2003.

CARNEY, A. Judith. Black rice: the african origians of rice cultivation in the Americas. Cambridge: Harvard University Press, 2001.

CHIAVENATO, Júlio José. O negro no Brasil. São Paulo: Brasiliense, 1996.

CURTIN, Philip D. The atlantic slave trade: a census. Madison: University of Wisconsin Press, 1969.

EL PAÍS. A autêntica revolução foi no período Neolítico. 2018. Guilherme Altares. Disponível em: https:// brasil.elpais.com/brasil/2018/04/20/ciencia/1524219983_369281.html. Acesso em: maio 2018.

FONSECA, Dagoberto José. A história, o africano e o afro-brasileiro. In: Cadernos de Formação - Ensino de História. São Paulo: Programa de Pedagogia Cidadã; Prograd; Unesp, 2004.

FONSECA, Dagoberto José. Contribuintes antigos - revendo a caderneta e os fiados. In: PAULA, Benjamin Xavier de. Educação, história e cultura da África e afro-brasileira. Franca, SP: Ribeirão Gráfica e Editora; Uberlândia, MG: Proex; UFU, 2008.

GLASSNER, Martin Ira. Political Geography. 2. ed. New York: J. Wiley, 1996.

NASCIMENTO, Elisa Larkin. Introdução às antigas civilizações africanas. In: (org.). NASCIMENTO, Elisa Larkin. Sankofa: matrizes africanas da cultura brasileira. Rio de Janeiro: Uerj, 1996.

MILLER, Joseph C. A dimensão histórica da África no Atlântico: açúcar, escravos e plantações. In: MOURÃO, Fernando Augusto de Albuquerque et al. (org.). A dimensão atlântica da África. São Paulo: CEA-USP; SDG-Marinha; Capes, 1997.

O PAÍs. Masekela preocupado com desvalorização das "línguas". 16/8/2017. Disponível em: http://opais. sapo.mz/masekela-preocupado-com-desvalorizacao-das-linguas. Acesso em: ago. 2018.

QUERINO, Manuel. Costumes africanos no Brasil. Recife: Massangana; Fundação Joaquim Nabuco, 1988. ROCHA, Rosa Margarida de Carvalho. Educação das relações étnico raciais: pensando referenciais para a organização de prática pedagógica. Belo Horizonte: Mazza Edições, 2007.

RUSSELL-WOOD, A. J. R. Technology and society: the impact of gold mining on the institution of slavery in portuguese américa. The Journal of Economic History, Cambridge, v. 37, n. 1, p. 59-83, 1977.

RUSSELL-WOOD, A. J. R. Através de um prisma africano: uma nova abordagem ao estudo da diáspora africana no Brasil Colonial. Revista Tempo, Niterói, RJ, n. 12, p. 11-50, 2001.

SANTOS, Aldenir Dias dos. Mulheres moçambicanas: resistência, associativismo, feminismo. 2016. 179fl. Tese (Doutorado em Ciências Sociais) - Pontifícia Universidade Católica de São Paulo - PUCSP, Programa de Pós-Graduação em Ciências Sociais, São Paulo, 2016. 